\title{
CONSTITUCIONALIZAÇÃO ULTRACÍCLICA E BIOTECNOLOGIA: ALTERNATIVAS REGULATÓRIAS
}

\section{ULTRACYCLICAL CONSTITUTIONALIZATION AND BIOTECHNOLOGY: REGULATORY}

\author{
ALTERNATIVES \\ Paulo Roberto Ramos Alves ${ }^{1 *}$
}

Licença CC BY:

Artigo distribuído sob os termos Creative Commons, permite uso e distribuição irrestrita em qualquer meio desde que $o$ autor credite a fonte original.

Resumo: A sociedade opera sob uma distinção binária sustentada pelos polos contrários da comunicação e não-comunicação, os discursos sociais fundem-se com base em distinções binárias secundárias, sendo novas distinções continuamente (re) produzidas de acordo com o aumento da complexidade da própria sociedade e de seus subsistemas, promovendo o esfacelamento da hierarquização jurídico-estatal ante novas perspectivas discursivas continuamente produzidas. A constitucionalização civil da comunicação biotecnológica permitiria a formatação relações contingenciais entre diversos setores organizacionais, fomentando o fortalecimento dos programas internos de cumprimento também a partir de uma imposição constitucional. Todavia, o traço distintivo dessa ideia reside exatamente na assimetria entre o conjunto de decisões estatais e as decisões corporativas. Essa assimetria permite, como já identificado, que o processo de constitucionalização biotecnológica ocorra de modo dialógico, rompendose com a tradicional noção de hierarquização normativa estatal.

Palavras-chave: Constituição; Biotecnologia; Regulação.

Abstract: The company operates under a binary distinction supported by the contrary poles of communication and non-communication, Society operates under a binary distinction social discourses merge on the basis of secondary binary distinctions, being new distinctions continuously (re)produced according to the increasing complexity of society itself and its subsystems, promoting the stoothing of the legal-state hierarchy in the face of new discursive perspectives continuously produced. The civil constitutionalization of biotechnological communication would allow the formatting of contingency relationships between various organizational sectors, strengthening internal compliance programs also from a constitutional imposition. However, the distinctive feature of this idea lies precisely in the asymmetry between the set of state decisions and corporate decisions. This asymmetry allows, as already identified, that the process of biotechnological constitutionalization occurs in a dialogical way, breaking with the traditional notion of state normative hierarchy.

Keywords: Constitution; Biotechnology; Regulation.

$1 \quad$ Doutor e Mestre em Direito pela Universidade do Vale do Rio dos Sinos - UNISINOS; estágio pós-doutoral pela Universidade de Passo Fundo - UPF; Advogado; pauloalvess@yahoo.com.br. 


\section{INTRODUÇÃO}

Já a algum tempo se percebe que a sociedade contemporânea se apresenta sob uma incrível multiplicidade de perspectivas, não podendo o Direito ser reduzido a uma narrativa única². Tal realidade foi denunciada por Warat quando percebeu o que chamou de polifonia ${ }^{3}$, onde os múltiplos discursos sociais fundem a visão do real enquanto horizonte de uma multiplicidade de sentidos. A própria e controversa noção de pós-modernidade impôs a lógica da inexistência de lógicas unitárias, rompendo-se com as grandes metanarrativas como narrou Lyotard ${ }^{4}$. Não obstante, outros diversos autores ${ }^{5}$ debruçaram-se à problemática questão envolvendo o enfraquecimento de determinadas instituições, bem como denunciando a fragmentação dos discursos atuais.

Sistemicamente esse problema foi profundamente analisado por Luhmann, Teubner e Neves, os quais identificam a sociedade contemporânea sob o signo da policontexturalidade, onde os múltiplos discursos fundem-se em uma unidade comunicativa que, por sua própria natureza, apenas pode existir enquanto sociedade. Integrando a sociedade, a comunicação jurídica também amolda-se sob tal perspectiva, fazendo com que se reconheça que a multiplicidade discursiva do momento atual é igualmente (re)produzida no interior do sistema jurídico, apontando para uma flagrante necessidade de rompimento para com um discurso jurídico amparado na ideia de centralização estatal ou, ainda, de uma regulação supranacional omniabarcante.

Sabendo-se que a sociedade opera sob uma distinção binária sustentada pelos polos contrários da comunicação e não-comunicação, os discursos sociais fundem-se com base em distinções binárias secundárias, sendo novas distinções continuamente (re)produzidas de acordo com o aumento da complexidade da própria sociedade e de seus subsistemas, promovendo o esfacelamento da hierarquização jurídico-estatal ante novas perspectivas discursivas continuamente produzidas ${ }^{6}$.

2 STAFFEN, Marcio Ricardo; ROSA, Alexandre Morais da. Dostoiévski e a polifonia do Direito: a síndrome do eterno marido na era das súmulas vinculantes. Revista de Estudos Constitucionais, Hermenêutica e Teoria do Direito (RECHTD). São Leopoldo: Unisinos. v. 3. n. 2. jul./dez. 2011. p. 187.

3 WARAT, Luis Alberto. A la fortune du pot. Seqüência. Florianópolis: UFSC. v. 05. n. 08. 1984. p. 37: "A polifonia é uma operação antilinear, uma técnica para colocar em crise a verdade. O sistema de signos tende a perder sua hegemonia quando é marcado por estruturas simultâneas de organização. A polifonia estimula a ruptura da estereotipação dos discursos, provoca o deslocamento permanente dos significados, não nos deixa hipnotizar com os álibis do real".

4 Sobre o conceito de pós-modernidade vide LYOTARD, Jean-François. A condição pós-moderna. 6. ed. Rio de Janeiro: José Olympio, 2000, p. XV.

5 A esse respeito vide igualmente BAUMAN, Zygmunt. O mal-estar da pós-modernidade. Rio de Janeiro: Jorge Zahar Editor, 1998. p. 153154; VATTIMO, Gianni. Posmodernidad: ¿una sociedad transparente? In: VATTIMO, Gianni et. al. En torno a la posmodernidad. Barcelona: Anthropos Editorial, 2003. p. 10; GIDDENS, Anthony. Risco, confiança, reflexividade. In: BECK, Ulrich; GIDDENS, Anthony; LASH, Scott. Modernização reflexiva: política, tradição e estética na ordem social moderna. São Paulo: UNESP, 1997. p. 220.

6 TEUBNER, Gunther. Os múltiplos corpos do rei: a autodestruição da hierarquia do Direito. In: Filosofia do direito e direito econômico que diálogo? Lisboa: Instituto Piaget, 1999. p. 340-341; 


\section{POLICONTEXTURALIDADE BIOTECNOLÓGICA E FONTES NORMATIVAS DIFUSAS}

Pode-se partir do pressuposto de que a policontexturalidade caracteriza-se pela multiplicidade de observações diversificadas - ainda que sobre um mesmo aspecto. Luhmann trabalha essa noção aduzindo que "un sistema [...] puede observarse a sí mismo simultánea o sucesivamente de maneras muy diversas - diríamos que policontexturales". ${ }^{7}$ Em outras palavras, a policontexturalidade designa, em primeiro lugar, a fragmentação de discursos sistêmicos e, em segundo, reflete a própria possibilidade de que tal fragmentação seja assimilada juridicamente, afirmando-se como uma proposta que permite a observação dos novos sentidos construídos pela teoria (e pela prática) jurídica. ${ }^{8}$ Para além da compreensão do sistema jurídico como um conjunto normativo escalonado, este afirma-se como uma esfera comunicativa que abrange todas aquelas comunicações que se amoldam à distinção direito/não-direito. A afirmação do sistema sob tais condições induz a sociedade a produzir comunicações relevantes desde a perspectiva biotecnojurídica, permitindo a inclusão sistêmica de comunicações que outrora não se revestiam sob a forma jurídica. É relevante afirmar que a juridicização da comunicação biotecnológica apenas torna-se possível a partir da produção de uma complexidade capaz de ser percebida biotecnojuridicamente, a qual ocorre junto a determinadas organizações enquanto esferas decisórias privilegiadas.

Conforme já mencionado, inúmeras são as declarações, convenções e tratados internacionais onde a preocupação com a evolução da biotecnologia é afirmada com grande saliência. Em um sistema jurídico policontextural globalmente interconectado, a operatividade do sistema jurídico necessariamente deve fazer referência a critérios normativos que ultrapassam a esfera estatal - e mesmo internacional -, estabelecendo-se relações dialógicas entre ordens normativas diversas como forma de uma possível gestão de risco. Esse diálogo é pressuposto em uma teoria que objetiva a observação do risco biotecnológico por um subsistema jurídico especialmente diferenciado diante dessa problemática. A opção pela perspectiva autopoiética, notadamente aquela assumida por Teubner, desvincula a produção jurídica da esfera estritamente estatal. Ao contrário da ótica kelseniana, onde o próprio Estado confunde-se com o Direito ${ }^{9}$ - eis que construto deste -, na perspectiva sistêmico-autopoiética o Estado passa a ser observado como uma organização que se reproduz mediante a lógica membro/não-membro ${ }^{10}$, definindo seus elementos a partir da produção de estruturas decisórias que asseguram sua existência.

LUHMANN, Niklas. La sociedad de la sociedad. Ciudad de México: Universidad Iberoamericana/Herder Editorial, 2007. p. 62.

ROCHA, Leonel Severo. Observações sobre a observação luhmanniana. In ROCHA, Leonel Severo, KING, Michael; SCHWARTZ, Germano. A verdade sobre a autopoiese no direito. Porto Alegre: Livraria do Advogado, 2009. p. 11-40., p. 39.

KELSEN, Teoria pura do direito, 2006, p. 316-317.

10 Observe-se, por exemplo, a definição constitucional dos critérios de nacionalidade e da respectiva diferença entre direitos e deveres imputáveis aos nacionais e estrangeiros. 
Tão logo esse aspecto seja reconhecido, uma constatação óbvia é que a vinculação DireitoEstado apenas pode ser dada de modo restritivo, ou seja, o Estado torna-se agrilhoado ao Direito que o próprio Direito diz que é Direito. Em outras palavras, ao se desenvolver em uma sociedade que se autodescreve como funcionalmente diferenciada, o sistema jurídico transcende sua intrínseca dependência da figura organizacional do Estado, identificando-se este como uma das esferas produtoras da normatividade. Mesmo que não se afirme no sentido da pax kantiana ${ }^{11}$, a sociedade mundial é tema central na ótica sistêmica. Ao se reconhecer uma sociedade comunicativa mundial, igualmente reconhece-se um Direito plural, difuso e dependente, por um lado, das mais diversas interfaces normativas disponíveis cuja operacionalidade funda-se na distinção direito/não-direito e, por outro, de uma integração comunicativa com diversos discursos sociais.

Com a integração da sociedade mundial determinados problemas são insuscetíveis de tratamento jurídico pelo recurso unitário à ordem estatal, reclamando o estabelecimento de diálogos entre ordens diversas, bem como da respectiva possibilidade de influências recíprocas. ${ }^{12}$ Diante das características do risco das biotécnicas - abstração, transtemporalidade, transterritorialidade e irreversibilidade - várias organizações manifestaram-se quanto ao tema por meio da construção de premissas decisórias tendentes a promover a absorção da incerteza e, igualmente, produzir ressonânciasjunto ao Biotecnodireito. Tal constatação implica na necessidade de observância daqueles programas organizacionais reconhecidamente voltados à atenção para os riscos biotecnológicos bem como de sua capacidade de resposta mediante o diálogo organizacional.

A influência do sistema jurídico internacional por meio da irritação legislativa originada pela internalização do conteúdo de tratados, declarações ou convenções e, ainda pelo reconhecimento judicial quanto ao conteúdo desses instrumentos normativos não é novidade na teoria do direito. Kelsen já afirmara o direito internacional como um direito externo capaz de abarcar o direito interno, moldando-se um sistema unitário plenamente integrado. ${ }^{13}$ Entretanto, a lógica da policontexturalidade rompe com a possibilidade de integração entre direito nacional e direito internacional no sentido de que aquele submete-se a este. Ao contrário, reconhece-se a existência autônoma dessas diferentes esferas da normatividade e, também, de outras ordens jurídicas diferenciadas em razão das particularidades do que lanni chamou de sociedade civil mundial. ${ }^{14} \mathrm{Com}$ isso, desloca-se o debate da esfera mantida pela distinção estatal/internacional para o diálogo organizacional em nível mundial

11 KANT, Immanuel. À Paz Perpétua. São Paulo: L\&PM, 1989. p. 33-34.

12 NEVES, Marcelo. Transconstitucionalismo. São Paulo: Martins Fontes, 2009, p. XXI

13 KELSEN, Hans. Teoria pura do direito. São Paulo: Martins Fontes, 2006., p. 366-369. Kelsen não observa a existência de um sistema jurídico mundial, mas limita-se à construção de uma teoria capaz de moldar o Direito mediante uma hierarquização normativa. Com base nesta hierarquização, Kelsen entende que inexistem conflitos entre o Direito internacional e o Direito estatal, bem como que são possíveis relações mútuas entre os sistemas normativos internacional e nacional. Essa integração seria dada pela submissão de um sistema normativo ao outro, moldando-se um sistema coerente e hierárquico que se apresentaria válido tanto no plano interno como no plano externo. Logo, a partir dessa teoria monista, haveria a necessária prevalência do ordenamento externo sobre o interno. 
que se coloca a partir da identificação do código direito/não-direito. Torna-se possível observar que existem inúmeras relações entre Direito e outros discursos sociais, bem como que o próprio Direito se diferencia internamente, possibilitando construções plurais no âmbito jurídico. Além da produção do Biotecnodireito como um sistema amparado em uma codificação dotada de tecnicidade específica, diferenciam-se intrajuridicamente complexos normativo-decisórios que restam amparados sob a distinção direito/não-direito. Nota-se o sistema jurídico como palco de desenvolvimento de estruturas periféricas e autônomas - como as codificações corporativas -, ainda que tal construção dê-se afastada da figura do estado-nacional. ${ }^{15}$

Ante o enfraquecimento da centralidade estatal, a sociedade passa a produzir um direito vivo, que emerge das instituições sociais fragmentadas e delimita seus próprios rumos diante da realidade comunicativa global. O desaparecimento da legislação política como esfera privilegiada da produção normativa cede lugar a um direito patchwork ${ }^{16}$ conformado em uma múltipla estrutura jurídica heterárquica. Sistemicamente o pluralismo jurídico (policontexturalidade) passa a ser observado como a unidade de discursos sociais fragmentários e autônomos que observam a realidade mediante o sentido atribuído pela distinção direito/não-direito. ${ }^{17}$ Uma das conclusões dos capítulos precedentes sugeriu a demarcação do risco biotecnológico a partir de sua ilicitude, o que permitiria a responsabilização meramente pela produção de um risco socialmente intolerável. Entretanto deve-se perceber que, apesar da possibilidade de responsabilização civil por riscos biotecnológicos ilícitos, o Biotecnodireito enfrenta um obstáculo evidente, derivado do complexo modelo de sociedade atual que redunda em sua observação como policontextural. Tal obstáculo diz respeito à própria observação do Direito como elemento essencialmente vinculado ao Estado. O que pensar da biotecnologia quando aquelas organizações que a produzem afirmam-se como dotadas de uma complexidade interna tal que lhes permite a atribuição de sentidos jurídicos às suas comunicações, sugerindo uma capacidade de auto-organização que transcende qualquer limite territorial, político ou jurídico-estatal?

Nesse contexto, a efetividade regulativa depende de uma coevolução entre racionalidades jurídicas diversas. ${ }^{18} \mathrm{O}$ Direito reconstrói a realidade extrasistêmica diante de sua lógica específica. Ao se reconhecer o Direito como policontextural - afinal, a própria sociedade o é -, realoca-se o problema da pluralidade de discursos jurídicos no interior do próprio sistema do Direito. Em outras palavras, a solução para os conflitos entre ordens normativas não pode ser dado por autoridades econômicas ou políticas, por exemplo, cabendo unicamente ao Direito sua reconstrução com

17 CARVALHO, Délton Winter de. Dano ambiental futuro: a responsabilização civil pelo dano ambiental. 2. ed. Porto Alegre: Livraria do Advogado, 2013. p. 46.

18 CARVALHO, Dano ambiental futuro. 2013, p. 46. 
base nessa pluralidade de vivências. Muito embora se entenda que as corporações transnacionais constituem-se na forma de complexos ordenamentos jurídicos autônomos, é interessante a posição de Neves sobre esse problema, eis que o autor o analisa sob a ótica de uma pretensão de autonomia, afirmando que as ordens transnacionais, ao mesmo tempo que enfrentam dificuldades quanto à sua constituição autônoma, igualmente afirmam uma pretensão de autonomia diante do Direito estatal, o que redunda no problema de um entrelaçamento comunicativo entre ordens jurídicas diversas e, por vezes, conflitantes. ${ }^{19}$ Essa realidade é espelhada por Teubner, quando afirma que o Direito global crescerá a partir da periferia da sociedade e não a partir de centros políticos vinculados aos estados nacionais ou instituições internacionais. ${ }^{20} \mathrm{E}$, justamente com base nesse crescimento periférico do sistema jurídico, torna-se possível observar alternativas sistêmicas para a gestão dos conflitos entre discursos jurídicos autônomos e para o consequente estabelecimento de elementos dialógicos para a gestão do risco biotecnológico.

Não é minimamente possível negligenciar que a comunicação biotecnológica, embora inicialmente desenvolvida pelo sistema da Ciência, encontra uma capacidade de produção de ressonâncias exatamente a partir de seu aproveitamento econômico. Ao apropriar-se da biotecnologia, a Economia passa a utilizá-la como um artefato interno de autorreprodução, culminando na formação organizacional de complexas corporações cuja autorreferencialidade aponta para a formação interna de mecanismos passíveis de identificação com o código binário do sistema jurídico. Não é demais afirmar que a comunicação biotecnológica expande-se para os mais diversos níveis organizacionais da sociedade mundial, especificando-se juridicamente de acordo com as particularidades da organização envolvida. Ademais, é possível perceber o sentido jurídicobiotecnológico - próprio do Biotecnodireito - como presente em discussões envolvendo Estados, a comunidade internacional, estruturas supranacionais e, por fim, reproduzida internamente nas corporações transnacionais imediatamente responsáveis pelo processo decisório que redunda na formação do risco biotecnológico.

Significa dizer que o código direito/não-direito e consequentemente a subdistinção biotecnojurídica podem ser reproduzidos no interior corporativo sob condições extremamente particulares de reiteração comunicativa, apontando para a formação de novas diferenciações propriamente jurídicas por estruturas que, em um primeiro nível de observação, não se relacionam diretamente com qualquer elemento do direito estatal. Ao contrário, a vinculação primária de tais

19 NEVES, Transconstitucionalismo, 2009, p. 184: "embora ordens jurídicas transnacionais tenham dificuldade de construir-se autonomamente perante os sistemas funcionais globais e as organizações com os quais estão estruturalmente vinculadas (economia, esporte, internet, organizações não-governamentais etc.), elas afirmam, exatamente com base na força dos respectivos sistemas funcionais e organizações, uma pretensão de autonomia perante o Direito estatal, do que resultam problemas de entrelaçamentos, no plano reflexivo de autofundamentação, entre elas e as ordens estatais."

20 TEUBNER, Gunther. A Bukowina global: sobre a emergência de um pluralismo jurídico transnacional. Impulso. Piracicaba: Unimep. v. 14. n. 33. jan.-abr. 2003, p. 14: "o direito mundial desenvolve-se a partir das periferias sociais, a partir das zonas de contato com outros sistemas sociais, e não no centro de instituições de Estados-nações ou de instituições internacionais." 
organizações se dá particularmente com a Economia, o que induz à autonomização, por exemplo, da lex mercatoria, como elemento conducente a novas maneiras de se perceber a sociedade e o Direito.

\section{CONSTITUCIONALIZAÇÃO ULTRACÍCLICA E BIOTECNOLOGIA}

Se existem normas corporativas desenvolvidas exatamente a partir de sua vinculação ao código direito/não-direito, o pensamento jurídico forçosamente é levado a reconhecer a igual viabilidade de um elemento constitucional capaz de operar em nível transnacional. Um dos grandes problemas que exsurgem de uma sociedade autodescrita como policontextural é sua possibilidade de integração em nível mundial. Questões relacionadas a violações de direitos humanos por parte de grandes corporações transnacionais ${ }^{21}$ ou a decisões tomadas pela OMC em nome de uma ampla liberdade comercial global refletem inegáveis problemas desde a ótica jurídica. Essas questões induzem o pensamento jurídico não apenas à percepção quanto ao reconhecimento de um problema de regulação política e jurídica mas, sobretudo, torna perceptível a problemática própria de uma regulação constitucional global. ${ }^{22}$

Muito embora seja possível identificar uma operacionalidade jurídica global e extraestatal fundada no código direito/não-direito, a policontexturalidade impõe fortes obstáculos quanto à busca por uma gestão confiável de risco. Seguramente pode-se afirmar que o recurso à autoridade estatal como estratégia única de gestão naufraga imediatamente, fazendo-se necessária a percepção quanto a formas alternativas de assimilação e gestão jurídica do risco biotecnológico. Uma tentativa interessante quanto à integração das diversas comunicações jurídicas foi proposta por Teubner a partir da evolução do conceito tradicional de hiperciclo de Eigen, o qual permitiria uma maior integração jurídica em nível mundial a partir de discussões de cunho constitucional.

Porém, como seria possível gerir o risco biotecnológico desde uma lógica constitucional que, como regra, reside agrilhoada à figura do estado-nação? ${ }^{23}$ Desde o final do século XVIII a dogmática jurídica homenageia o constitucionalismo como elemento conducente à limitação do poder soberano pelo deslocamento do poder individual para a abstração estatal ou, ainda, como o elemento criador/

21 Sobre tal aspecto, narra TEUBNER, Gunther. Globalized society - fragmented justice: human rights violations by "private" transnational actors. In: ESCAMILLA, Manuel; SAAVEDRA, Modesto (eds.). Law and Justice in a global society. Granada: International Association for philosophy of law and social philosophy, 2005. p. 547-548: "The 'horizontal' effect of fundamental rights, i.e. the question whether they impose obligations not only on governmental bodies but also directly on private actors, is taking on much more dramatic dimensions in the transnational sphere than it ever had nationally. It not only arises for human-rights infringements by pharmaceutical enterprises in the worldwide AIDS epidemic, but has already raised a stir in several scandals in which multinational enterprises were involved. I shall single out a few glaring cases: environmental pollution and inhuman treatment of local population groups, e.g. by Shell in Nigeria; the chemical accident in Bhopal; disgraceful working conditions in 'sweatshops' in Asia and Latin America; child labour at IKEA and NIKE; accusations that multinational enterprises in Myanmar were collaborating with a dictatorial regime; the suspicions levied against sports goods manufacturer Adidas of having footballs produced in China by forced labour; the use of highly poisonous pesticides in banana plantations; disappearances of unionized workers; environmental damage from big construction projects. The list could easily be extended."

22 TEUBNER, Gunther. Nuovi confliti costituzionali. Milão/Turim: Bruno Mondadori, 2012. p. 3.

23 Exemplificativamente, a Constituição Brasileira de 1988 assegura a precaução e a equidade intergeracional como elementos prioritários para a gestão do risco biotecnológico, entretanto, essa é a lógica constante no sistema jurídico brasileiro, cujo conteúdo não é imediatamente percebido ou assimilado por desde a ótica jurídica por corporações extra estatais. 
balizador do Direito e elemento estruturante do Estado. A adoção dessa ótica sugere intransponíveis barreiras na tarefa de gerenciamento jurídico do risco biotecnológico, razão pela qual o próprio conceito de constituição passa por uma necessária redescrição diante da policontexturalidade jurídica.

Sob uma observação sistêmica, a Constituição passa a ser observada como uma forma dotada de extrema especificidade na sociedade contemporânea. Ademais, a Constituição apresenta-se como uma forma muito evolutiva de comunicação no interior do sistema social. Nesse contexto, rompese com a possibilidade de observação das constituições como fundamentos da normatividade estatal, vinculando-as a uma prática circular e autorreferente. Luhmann observa que as constituições afiguram-se na forma de uma reação à diferenciação entre Direto e Política, separando esses dois âmbitos funcionais e, paradoxalmente, religando-os. ${ }^{24}$ Direito e Política, então, convergem para uma coexistência comunicativa, sem que haja a juridicização da Política ou a politização do Direito.

Rodotà investiga essa questão aduzindo a necessidade de uma desestruturação/estruturação entre as esferas pública e privada, identificando na Internet um caminho interessante para essa reconstrução em razão daquela se constituir como "el mayor espacio público que la humanidad haya conocido". Sob tal perspectiva, as reflexões sobre a Internet poderiam conduzir à um possível constitucionalismo global descentralizado, cuja expansão ocorreria horizontalmente entre ordens jurídicas estruturadas para enfrentar os desafios impostos pelas novas tecnologias. ${ }^{25}$

A ideia de constitucionalismo adquire uma interessante conotação sistêmica quando observado a partir de uma perspectiva evolucionista, na qual se rompe com a possibilidade de uma constituição vinculada aos critérios modernos de supremacia, e verticalidade hierárquica para, então, considerar uma realidade fundada na existência de sistemas sociais que operam comunicativamente bem como constantemente diferenciam-se diante de seus ambientes. Conforme já visto quando enfrentada a questão da evolução do Direito, sua autopoiese desenvolve-se mediante três fases distintas: em uma primeira fase os elementos jurídicos (elementos, estruturas, processos e limites) confundem-se aos elementos da comunicação geral, sendo determinados de forma heterônoma. Uma segunda fase é observada quando o Direito passa a construir os seus próprios elementos e a utilizá-los enquanto operações jurídicas. Por fim, a autonomia jurídica apenas é identificada - e somente assim se pode falar em um Direito autopoiético - a partir da articulação dos elementos do sistema de forma autorreferente e circular, caracterizando um hiperciclo ${ }^{26}$.

24 LUHMANN, Niklas. La costituzione come acquisizione evolutiva. In: ZAGREBELSKY, Gustavo; PORTINARO, Pier Paolo; LUTHER, Jörg. Il futuro della costituzione. Torino: Einaudi, 1996. (LUHMANN, Niklas. A Constituição como aquisição evolutiva. Tradução livre feita por Menelick de Carvalho Netto, Giancarlo Corsi e Raffaele de Giorgi). p. 4.

25 RODOTÀ, Stefano. EI derecho a tener derechos. Madrid: Trotta, 2014, p. 385.

26 TEUBNER, Gunther. O direito como sistema autopoiético. Lisboa: Fundação Calouste Gulbenkian, 1989. p. 77. 
Demarcada a autonomia do sistema jurídico, Teubner radicaliza a própria ideia de circularidade a partir da distinção entre hipercilio e ultraciclo. Enquanto o hiperciclo refere-se à ideia de uma articulação autorreferente a circular dos elementos jurídicos - o que ocorre em uma rede fechada -, o ultraciclo surge no momento em que determinados ciclos de perturbações recíprocas desenvolvemse com referência a essas redes fechadas. Isso significa que, no âmbito dos códigos corporativos públicos e privados particularmente identificados, as ligações jurídicas caracterizam-se de forma hipercíclica, enquanto as relações estabelecidas entre códigos jurídicos privados e públicos revestemse na forma ultracíclica ${ }^{27}$, o que permite uma integração comunicativa entre as diversas organizações que, amparadas em códigos corporativos privados, reproduzem o risco biotecnológico alheias à determinações constitucionais (estatais) objetivas. Importa dizer que as constituições nacionais (ou, ainda, as supranacionais) não são capazes de determinar o âmbito de validade das normatizações intracorporativas daquelas organizações voltadas à biotecnologia. Os códigos estatais não delimitam o círculo de validade das normas corporativas, mas caracterizam-se como impulsos a serem observados pela lógica da específica da organização. A assimilação de tais perturbações, entretanto, não é dada externamente - pela normatização estatal - mas sim pelos próprios processos internos de tais organizações privadas 28

Vale salientar que não se assiste a uma mera divisão de critérios jurídicos, mas sim a formação de sistemas jurídicos específicos - como a lex mercatoria, a lex laboris, a lex sportiva internacionalis ou a lex digitalis - sem qualquer vinculação ao Estado. Nesse aspecto, as necessidades de normatização vão muito além da mera regulação pública, desenvolvendo-se complexos de relações jurídicas como produtos de private governance regimes ${ }^{29}$, compreendendo-se a biotecnologia como elemento de interesse quando da formação de tais regimes privados.

O processo de constitucionalização de atores privados transnacionais passa a ser resultado de uma observação diferenciada da Constituição, qual seja, na possibilidade de um constitucionalismo capaz de promover diálogos entre racionalidades sistêmicas distintas. Se, como regra geral, a biotecnologia é produzida no interior de complexas organizações cujas operações permitem identificar a formação de estruturas que convergem em regimes jurídicos privados, é natural que se perceba que qualquer imposição verticalizada por parte de estados ou organismos internacionais torna-se inócua, eis que tais mecanismos não são capazes de suplantar a complexidade intraorganizacional das corporações transnacionais, mantendo-se incólume a problemática do risco biotecnológico. 
O incremento da complexidade corporativa aponta para questões fundamentais para a teoria do direito e da sociedade. Paradoxalmente, a incapacidade de delimitação objetiva das normas intracorporativas torna-se requisito para sua reconstrução com base em interesses sociais capazes de convergir em interesses corporativos. A própria observância aos direitos humanos, por exemplo, passa a encontrar, no âmbito organizacional, uma esfera dotada de grande especificidade: a normatização organizacional torna-se capaz de impor a seus membros, por exemplo, a observância a direitos e garantias fundamentais ou a necessária cautela diante do desenvolvimento da biotecnologia.

A busca pela autonomia corporativa (organizacional) é marco central na ideia de autoconstitucionalização de atores corporativos privados. Diante da realidade policontextural que caracteriza a sociedade contemporânea, essa busca por autonomia reflete na proposta de constituições corporativas, identificando-se em tal construção um duplo viés: em primeiro lugar, a liberação - de corporações transnacionais privadas - da normatividade estatal e, em segundo, o fomento à construção de estruturas globais destinadas à segurança de suas transações. ${ }^{30}$

Esse fenômeno espelha uma realidade cada vez mais presente na sociedade diferenciada: a autonomia corporativa depende de determinados fatores, eis que as organizações adquirem certa especificidade funcional a partir da recursividade de suas operações e sua consequente aceitação na sociedade global. Enquanto comunicações decisoriamente produzidas no âmbito organizacional, essa normatividade corporativa passa a construir critérios jurídicos capazes de culminar em uma genuína teoria de cunho jurídico-constitucional. Teubner explica essa possibilidade aduzindo que a constitucionalização é uma tendência atual junto à normatização das corporações transnacionais. Nesse contexto, a própria ideia de Constituição transcende a tradicional vinculação ao Estado nacional, amoldando-se diante de ordens jurídicas dotadas de plena autonomia operacional. Neste processo, a noção de constituição não mais se vincula a um sistema político central, deslocando-se para agentes corporativos descentralizados então capazes de produzirem normas voltadas à sua própria auto-organização. ${ }^{31}$

O processo de (auto)constitucionalização de atores corporativos transnacionais vincula-se, primeiramente, a uma visão alternativa do próprio direito constitucional. Essa nova visão depende, em imensa medida, do reconhecimento da policontexturalidade jurídica. Não é à toa que a própria ideia de autopoiese, em Teubner, vincula-se à policontexturalidade do Direito, como afirma Rocha ${ }^{32}$.

30 TEUBNER, Auconstitucionalização das corporações transnacionais?, 2012,p. 113.

31 TEUBNER, Auconstitucionalização das corporações transnacionais?, 2012, p. 111: "materializam-se nessa dinâmica não apenas tendências de uma juridicização, mas também de uma constitucionalização. Ambos os tipos de códigos corporativos tomados em conjunto representam o advento de constituições corporativas transnacionais específicas - concebidas como constituições no sentido estrito. [...] esse argumento é baseado em um conceito de constituição que não está limitado ao Estado nacional e implica que também ordens sociais não estatais desenvolvam constituições autônomas sob circunstâncias históricas particulares. Além disso, no processo globalizante, o centro de constitucionalização desloca-se do sistema político para diferentes setores sociais, que produzem normas constitucionais de cunho civilsocietário paralelamente às constituições dos Estados nacionais." 
Quando se fala em constitucionalização das esferas corporativas privadas deve-se perceber uma urgente distinção entre funções e estruturas constitucionais. As funções, caracterizadas como regras constitutivas e limitadoras, revestir-se-iam na possibilidade, por um lado, de assegurar a autonomia corporativa (mesmo diante do Estado), possibilitando a operacionalidade dos empreendimentos em nível global, o que efetivamente já se verifica em relação à comunicação biotecnológica. Por outro lado, a constitucionalização seria estabelecida com uma função limitadora, pois permitiria que os códigos corporativos restringissem determinadas atividades corporativas em razão de uma responsabilidade pública internamente percebida. ${ }^{33}$

A constituição corporativa seria caracterizaria estruturalmente pelos critérios da dupla reflexividade e da metacodificação binária. Em um primeiro nível estrutural, a constituição corporativa - enquanto norma diferenciada - depende de arranjos procedimentais capazes de assegurar a manutenção das regras primárias constitucionalmente estabelecidas, o que se daria por meio de controles organizacionais internos, então capazes de estabelecer critérios para a implementação, interpretação ou modificação das determinações constitucionais. Como se vê, a lógica é idêntica à do sistema jurídico estatal, no qual a normatividade funda-se na operacionalidade do próprio Direito, afirmando-se o sistema jurídico mediante uma construção circular e autorreferente..$^{34}$

Canotilho ${ }^{35}$ aponta para dimensões constitutivas e caracterizadoras das constituições civis como associadas ao constitucionalismo político. Tais dimensões se apresentariam por meio 1) da regulação jurídica da Constituição Civil por meio de acoplamentos entre o sistema social e as estruturas reguladoras do sistema; 2) pela hierarquização normativa intracorporativa, construindo-se uma diferença interna entre normas constitucionais e regulamentação ordinária; 3) por meio do controle material exercido por instâncias jurisdicionais ou com poderes judiciais; 4) pela organização da constituição sob a forma de procedimentos e processos formais que delimitem seus aspectos regulativos.

Por outro lado, mostra-se igualmente necessária a construção de uma codificação capaz de assegurar as operações do Direito corporativo. Teubner ${ }^{36}$ propõe a delimitação de uma metacodificação binária da constituição corporativa, conduzindo-se a operações subordinadas ao código constitucional/inconstitucional e, logo, percebendo-se que a metacodificação enviaria, de forma reflexiva, todas as operações corporativas - incluindo-se as econômicas - à observância dos critérios normativos da constituição corporativa. Essa realidade, contudo, depende de uma grande

33 TEUBNER, Auconstitucionalização das corporações transnacionais?, 2012, p. 113-114

34 TEUBNER, Auconstitucionalização das corporações transnacionais?, 2012, p. 111.

35 CANOTILHO, José Joaquim Gomes. Brancosos e interconstitucionalidade: itinerários dos discursos sobre a historicidade constitucional. 2. ed. Coimbra: Almedida, 2008. p. 297.

36 TEUBNER, Auconstitucionalização das corporações transnacionais?, 2012, p. 117: "a metacodificação é, dessa forma, um híbrido. Ela serve como unidade fictícia para dois controles de constitucionalidade diferentes dentro da corporação. Ela está localizada, de um lado, hierarquicamente acima do código binário jurídico e, de outro, acima do econômico. Assim, ela assume um sentido diferente conforme o código que controla - se o econômico ou o jurídico. Em contextos econômicos, funciona de modo a refletir a responsabilidade social da empresa e procura identificar estratégias de atividades econômicas ambientalmente corretas. No contexto do direito corporativo, introduz a distinção entre direito simples e constitucional e controla a adequação de atos legais simples aos valores e princípios estabelecidos na constituição corporativa". Leia-se igualmente TEUBNER, Nuovi confliti costituzionali, 2012, p. 119-120. 
revisão na clássica teoria do Estado, buscando-se a construção de novos rumos para a prática jurídica ${ }^{37}$ e, via de consequência, permitindo-se a produção de alternativas para alocar a perspectiva do Biotecnodireito desde o reconhecimento da policontexturalidade.

Pensar em um constitucionalismo corporativo é extremamente interessante diante da necessidade de harmonização entre códigos jurídicos públicos e privados, pois possibilitaria a alocação do sentido biotecnojurídico no próprio marco constitucional corporativo, atribuindo a tais organizações uma operacionalidade voltada à produção da comunicação biotecnológica desde a observância daqueles elementos centrais para a gestão biotecnojurídica de risco. Significa dizer que, como a própria evolução do constitucionalismo estatal, onde gradativamente foram construídas perspectivas de liberdade e igualdade, o constitucionalismo corporativo também se insere em um contexto evolutivo, mostrando-se cabível a inserção de elementos como o risco biotecnológico enquanto critério balizador dos processos decisórios corporativos.

A estratégia de constitucionalização extraestatal da comunicação biotecnológica dependeria, contudo, de elementos do sistema jurídico capazes de assimilarem a complexidade da distinção biologicamente-aplicável/biologicamente-inaplicável. Sendo uma comunicação que ultrapassa fronteiras estatais, a biotecnologia ingressaria no sistema jurídico enquanto comunicação própria do Biotecnodireito, fomentando a demarcação constitucional de seus limites em um âmbito global de aplicabilidade. Por assim dizer, a inserção da comunicação biotecnológica no marco de um constitucionalismo global - o que pode ser pensado desde a perspectiva de Teubner - construiria limites decisórios aplicáveis organizacionalmente, possibilitando a seletivização da comunicação biotecnológica desde as estruturas organizacionais que a fomenta.

\section{CONSIDERAÇÕES FINAIS}

Pode-se notar que uma possível constitucionalização civil da comunicação biotecnológica permitiria a formatação relações contingenciais entre diversos setores organizacionais, fomentando o fortalecimento dos programas internos de cumprimento também a partir de uma imposição constitucional. Todavia, o traço distintivo dessa ideia reside exatamente na assimetria entre o conjunto de decisões estatais e as decisões corporativas. Essa assimetria permite, como já identificado, que o processo de constitucionalização biotecnológica ocorra de modo dialógico, rompendo-se com a

$37 \quad$ Há uma evidente tensão, pois, entre Direito e Estado. Isso é ilustrado por Neves quando afirma que no modelo do Estado Democrático de Direito há uma necessidade de integração entre o Direito (Têmis) e o Estado (Leviatã), havendo a constatação de que "nesse tipo de Estado, Têmis deixa de ser um símbolo abstrato de justiça para se tornar uma referência real e concreta de orientação da atividade de Leviatã. Este, por sua vez, é rearticulado para superar a sua tendência expansiva, incompatível com a complexidade sistêmica e a pluralida de interesses, valores e discursos da sociedade moderna. Não se trata apenas de uma fórmula para 'domesticar' ou 'domar' o Leviatã. Antes, o problema consiste em estabelecer, apesar das tensões e conflitos, uma relação construtiva entre Têmis e Leviatã, de tal maneira que o direito não se mantenha como uma mera abstração e o poder político não se torne impotente por sua hipertrofia ou falta de referência legitimadora." NEVES, Marcelo. Entre Têmis e Leviatã: uma relação difícil. São Paulo: Martins Fontes, 2006. p. XIX. 
tradicional noção de hierarquização normativa estatal. Uma constatação necessária: especificamente o processo de constitucionalização biotecnológica pode ser atribuído ao Biotecnodireito enquanto subsistema jurídico. Nesse sentido, a circularidade restritiva da comunicação biotecnojurídica fomenta a crescente complexificação do Direito, redundando na produção de comunicações que necessariamente serão percebidas corporativamente. Partindo da dialogicidade e do reconhecimento da pluralidade, o subsistema biotecnojurídico pode igualmente atuar como um atrator juridicamente condicionante no interior do Direito, produzindo uma seletividade comunicativa capaz de ser igualmente absorvida sob a perspectiva constitucional/inconstitucional, bem como ampliando os reflexos dessa comunicação sob a forma de irritações ou perturbações a serem assimiladas por outras esferas sociais.

A realidade jurídica das grandes corporações inegavelmente escapa da juridicização estatal, havendo a necessidade de construções que levem em consideração a policontexturalidade da sociedade bem como a flagrante existência de conflitos entre ordens normativas distintas. Tal modelo conduz diretamente à uma teorização jurídico-constitucional não condizente com a inócua tentativa de verticalização normativa entre estado e corporações privadas mas, antes, do estabelecimento da dialogicidade como elemento próprio de integração jurídica para a gestão do risco biotecnológico.

\section{REFERÊNCIAS}

BAUMAN, Zygmunt. O mal-estar da pós-modernidade. Rio de Janeiro: Jorge Zahar Editor, 1998.

CANOTILHO, José Joaquim Gomes. Brancosos e interconstitucionalidade: itinerários dos discursos sobre a historicidade constitucional. 2. ed. Coimbra: Almedida, 2008.

GIDDENS, Anthony. Risco, confiança, reflexividade. In: BECK, Ulrich; GIDDENS, Anthony; LASH, Scott. Modernização reflexiva: política, tradição e estética na ordem social moderna. São Paulo: UNESP, 1997.

IANNI, Octavio. A sociedade global. 12. ed. Rio de Janeiro: Civilização Brasileira, 2005.

KANT, Immanuel. À Paz Perpétua. São Paulo: L\&PM, 1989.

KELSEN, Hans. Teoria pura do direito. São Paulo: Martins Fontes, 2006.

LUHMANN, Niklas. La costituzione come acquisizione evolutiva. In: ZAGREBELSKY, Gustavo; PORTINARO, Pier Paolo; LUTHER, Jörg. Il futuro della costituzione. Torino: Einaudi, 1996. (LUHMANN, Niklas. A Constituição como aquisição evolutiva. Tradução livre feita por Menelick de Carvalho Netto, Giancarlo Corsi e Raffaele de Giorgi).

LUHMANN, Niklas. La sociedad de la sociedad. Ciudad de México: Universidad Iberoamericana/Herder Editorial, 2007.

LYOTARD, Jean-François. A condição pós-moderna. 6. ed. Rio de Janeiro: José Olympio, 2000.

NEVES, Marcelo. Entre Têmis e Leviatã: uma relação difícil. São Paulo: Martins Fontes, 2006.

NEVES, Marcelo. Transconstitucionalismo. São Paulo: Martins Fontes, 2009.

ROCHA, Leonel Severo. A produção autopoiética do sentido do direito. Direitos Culturais, Santo Ângelo, v. 4, n. 7, jul./ dez. 2009. 
ROCHA, Leonel Severo. Observações sobre a observação luhmanniana. In ROCHA, Leonel Severo, KING, Michael; SCHWARTZ, Germano. A verdade sobre a autopoiese no direito. Porto Alegre: Livraria do Advogado, 2009.

RODOTÀ, Stefano. El derecho a tener derechos. Madrid: Trotta, 2014.

STAFFEN, Marcio Ricardo; ROSA, Alexandre Morais da. Dostoiévski e a polifonia do Direito: a síndrome do eterno marido na era das súmulas vinculantes. Revista de Estudos Constitucionais, Hermenêutica e Teoria do Direito (RECHTD). São Leopoldo: Unisinos. v. 3. n. 2. jul./dez. 2011.

TEUBNER, Gunther. A Bukowina global: sobre a emergência de um pluralismo jurídico transnacional. Impulso. Piracicaba: Unimep. v. 14. n. 33. jan.-abr. 2003

TEUBNER, Gunther. Direito, sistema e policontexturalidade. Piracicaba: Unimep, 2005.

TEUBNER, Gunther. Globalized society - fragmented justice: human rights violations by "private" transnational actors. In: ESCAMILLA, Manuel; SAAVEDRA, Modesto (eds.). Law and Justice in a global society. Granada: International Association for philosophy of law and social philosophy, 2005.

TEUBNER, Gunther. Nuovi confliti costituzionali. Milão/Turim: Bruno Mondadori, 2012.

TEUBNER, Gunther. O direito como sistema autopoiético. Lisboa: Fundação Calouste Gulbenkian, 1989.

TEUBNER, Gunther. Os múltiplos corpos do rei: a autodestruição da hierarquia do Direito. In: Filosofia do direito e direito econômico que diálogo? Lisboa: Instituto Piaget, 1999.

VATTIMO, Gianni. Posmodernidad: ¿una sociedad transparente? In: VATTIMO, Gianni et. al. En torno a la posmodernidad. Barcelona: Anthropos Editorial, 2003.

WARAT, Luis Alberto. A la fortune du pot. Seqüência. Florianópolis: UFSC. v. 05. n. 08. 1984.

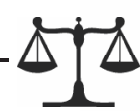

